\title{
A Study on the Effect of Nudging on Long-Term Boundary Layer Profiles of Wind and Weibull Distribution Parameters in a Rural Coastal Area.
}

\author{
Gryning, Sven-Erik; Batchvarova, Ekaterina; Floors, Rogier
}

Published in:

Journal of Applied Meteorology and Climatology

Link to article, DOI:

10.1175/JAMC-D-12-0319.1

Publication date:

2013

Document Version

Publisher's PDF, also known as Version of record

Link back to DTU Orbit

Citation (APA):

Gryning, S-E., Batchvarova, E., \& Floors, R. (2013). A Study on the Effect of Nudging on Long-Term Boundary Layer Profiles of Wind and Weibull Distribution Parameters in a Rural Coastal Area. Journal of Applied Meteorology and Climatology, 52(5), 1201-1207. https://doi.org/10.1175/JAMC-D-12-0319.1

\section{General rights}

Copyright and moral rights for the publications made accessible in the public portal are retained by the authors and/or other copyright owners and it is a condition of accessing publications that users recognise and abide by the legal requirements associated with these rights.

- Users may download and print one copy of any publication from the public portal for the purpose of private study or research.

- You may not further distribute the material or use it for any profit-making activity or commercial gain

- You may freely distribute the URL identifying the publication in the public portal 


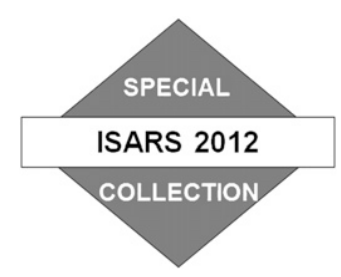

\title{
A Study on the Effect of Nudging on Long-Term Boundary Layer Profiles of Wind and Weibull Distribution Parameters in a Rural Coastal Area
}

\author{
S.-E. GRYNING \\ DTU Wind Energy, Ris $\varnothing$ Campus, Technical University of Denmark, Roskilde, Denmark \\ E. BATCHVAROVA \\ DTU Wind Energy, Risø Campus, Technical University of Denmark, Roskilde, Denmark, and National Institute of Meteorology \\ and Hydrology, Sofia, Bulgaria \\ R. FLOORS \\ DTU Wind Energy, Risø Campus, Technical University of Denmark, Roskilde, Denmark
}

(Manuscript received 29 November 2012, in final form 22 January 2013)

\begin{abstract}
By use of $1 \mathrm{yr}$ of measurements performed with a wind lidar up to 600-m height, in combination with a tall meteorological tower, the impact of nudging on the simulated wind profile at a flat coastal site (Høvsøre) in western Denmark using the Advanced Research version of the Weather Research and Forecasting model (WRF) is studied. It was found that the mean wind speed, the wind direction change with height, and the wind power density profiles are underestimated with the configuration of WRF used and that the impact of nudging on the simulated mean values was minor. Nudging was found to reduce the scatter between the simulated and measured wind speeds, expressed by the root-mean-square error, by about $20 \%$ between altitudes of 100 and $500 \mathrm{~m}$. The root-mean-square error was nearly constant with height for the nudged case $\left(\sim 2.2 \mathrm{~m} \mathrm{~s}^{-1}\right)$ and slightly increased with height for the nonnudged one, reaching $2.8 \mathrm{~m} \mathrm{~s}^{-1}$ at 300 and $500 \mathrm{~m}$. In studying the long-term wind speed variability with the Weibull distribution, it was found that nudging had a minor effect on the scale parameter profile, which is closely connected to the mean wind speed. Improvement by nudging was seen on the profile of the shape parameter. Without nudging, the shape parameter was underestimated at all heights; with nudging, the agreement was good up to about $100 \mathrm{~m}$ and above that height the shape parameter was underestimated.
\end{abstract}

\section{Introduction}

The two-parameter Weibull distribution of the wind speed is commonly used in wind-energy investigations. The available wind power density is proportional to the mean cube of the wind speed, which depends on both the scale and shape parameters used to describe a Weibull distribution. These parameters can be estimated from long-term measurements or modeled data of the wind field.

Wind observations from within the boundary layer are often not assimilated because of large discrepancies

Corresponding author address: S.-E. Gryning, DTU Wind Energy, Ris $\varnothing$ Campus, Technical University of Denmark, Frederiksborgvej 399, 4000 Roskilde, Denmark.

E-mail:sveg@dtu.dk between measurements and model counterparts that are due to local terrain effects (Hahmann et al. 2010; Boilley and Mahfouf 2012). Observed wind speeds at greater heights can show large differences when using different reanalysis data to reinitialize the Weather Research and Forecasting (WRF) model (Floors et al. 2013). Verification of data assimilation techniques is now possible with the advent of new types of instruments, such as wind Doppler lidars, that observe winds with high temporal and vertical resolution and that have become popular research tools for studying the boundary layer structure (O'Connor et al. 2010).

Nudging, as well as other types of assimilation, relaxes the regional-model solution toward the driving global analysis (Deng and Stauffer 2005; Otte 2007), which ensures that solutions of the regional model do not drift 
from the synoptic-scale structures captured by the analysis. Lo et al. (2008) found that applying nudging from the coarse-resolution analysis improved the skill of the regional model for pressure, temperature, geopotential height, wind, and humidity.

Another way to limit this drift relies on periodic reinitialization of the simulations (Lo et al. 2008). Because considerable spinup time is required for each reinitialization, such an approach is computationally expensive. Von Storch et al. (2000) showed that some slowly varying meteorological parameters (e.g., soil moisture) that are essential for long-term calculations might be lost when applying reinitializations.

Here we present a case study of the impact of nudging on the profiles of wind and Weibull distribution parameters at a coastal site. The simulations are compared with $1 \mathrm{yr}$ of wind profile measurements performed with a wind lidar up to $600 \mathrm{~m}$ in height. The nudging was performed for wind, temperature, and humidity from a global model to the outermost domain in the WRF model. We investigate the ability of the WRF meteorological model to simulate the profiles of mean wind, power density, and the shape and scale parameters describing the Weibull distribution.

\section{Site and measurements}

The study covers the period 23 April 2010-31 March 2011. The measurements were carried out at the Danish National Test Station of Wind Turbines at Høvsøre (Gryning et al. 2007), Denmark, which is located on the western coast of Jutland. Except for the presence of the North Sea to the west and a shallow lake to the south, the terrain is flat and homogeneous, consisting of grass, various agricultural crops, and a few shrubs. The intensively instrumented $116.5-\mathrm{m}$ meteorological mast $\left(56^{\circ} 26^{\prime} 26.0^{\prime \prime} \mathrm{N}, 8^{\circ} 9^{\prime} 3.1^{\prime \prime} \mathrm{E}\right)$ is located about $1.8 \mathrm{~km}$ east of the coastline and $200 \mathrm{~m}$ south of the closest wind-turbine stands. Observations from the 160-m top level of the light mast $300 \mathrm{~m}$ north of the meteorological tower were also used. Wind speed is measured at 10,40, 60, 80, 100, 116.5 , and $160 \mathrm{~m}$ with Risø P2546 cup anemometers (Pedersen 2004), and the wind direction at 10, 60,100, and $160 \mathrm{~m}$ is measured with wind vanes on booms directed to the south.

A pulsed wind Doppler lidar (Leosphere WLS70) was operated during the campaign and was located about $20 \mathrm{~m}$ west of the meteorological mast. The wind Doppler lidar is equipped with a rotating silicon prism that provides an optical scanning cone of $15^{\circ}$ to zenith. The lidar scans the atmosphere at four azimuth angles separated by $90^{\circ}$. One $360^{\circ}$ full scan (rotation) is performed approximately every $30 \mathrm{~s}$. The Doppler shift-based measurements of the wind are available every $50 \mathrm{~m}$ from $100 \mathrm{~m}$ above the ground to approximately $1-2-\mathrm{km}$ height; the maximum altitude is dependent on the attainable 10-min-averaged carrier-to-noise ratio (CNR). The maximum measuring height is often determined by cloud-base height, after which the lidar signal (1.55-nm wavelength) is rapidly attenuated.

\section{Numerical modeling}

Wind profiles are predicted using the Advanced Research version of the WRF model, version 3.2.1, developed by the National Center for Atmospheric Research (Skamarock et al. 2008). It is a numerical weather prediction and atmospheric simulation system that is designed for both research and operational applications. Here, the model simulations are performed in long-term analysis mode. The model setup includes the "Noah" land surface scheme (Chen and Dudhia 2001), the Thompson microphysics scheme (Thompson et al. 2004), the planetary boundary layer scheme of MellorYamada/Nakanishi and Niino, level 2.5 (Nakanishi 2001), and its corresponding surface-layer scheme. The WRF model is configured to calculate the meteorological parameters at 41 vertical levels from the surface to the 100-hPa pressure level. Eight of these levels are within the 600-m height extent of interest to this study, with the first model level at $14 \mathrm{~m}$. Initial and boundary condition are taken from the Global Final Analyses data (FNL) every $6 \mathrm{~h}$ on a $1^{\circ} \times 1^{\circ}$ grid. The real-time global sea surface temperature analysis from the National Centers for Environmental Prediction was used. Two domains were used, one with a horizontal grid size of $18 \mathrm{~km}$ ranging from $7.12^{\circ} \mathrm{W}$ to $22.9^{\circ} \mathrm{E}$ and from $49.1^{\circ}$ to $65.2^{\circ} \mathrm{N}$ with a time step of $120 \mathrm{~s}$ and one with a horizontal grid size of $6 \mathrm{~km}$ ranging from $3.57^{\circ}$ to $17.4^{\circ} \mathrm{E}$ and from $53.1^{\circ}$ to $59.7^{\circ} \mathrm{N}$ with a time step of $40 \mathrm{~s}$. The simulations are initialized every 10 days at 1200 UTC, and, after a spinup time of $24 \mathrm{~h}$, a time series of 10-min simulated meteorological forecast data from 25 to $264 \mathrm{~h}$ is generated. The model is run both without nudging and with nudging toward the FNL analysis. Nudging is applied for the wind, temperature, and humidity above the 10th model level, which approximately corresponds to $1400 \mathrm{~m}$, on the outermost model domain during the whole simulation period. Except for the nudging, the configurations of the model simulations are the same.

\section{Climatological description of the wind profile}

The wind rose and total distribution of the wind speed from the lidar at $100 \mathrm{~m}$ are shown in Fig. 1, from which it is seen that the wind at $\mathrm{H} \varnothing \mathrm{vs} \varnothing \mathrm{re}$ is predominantly from 

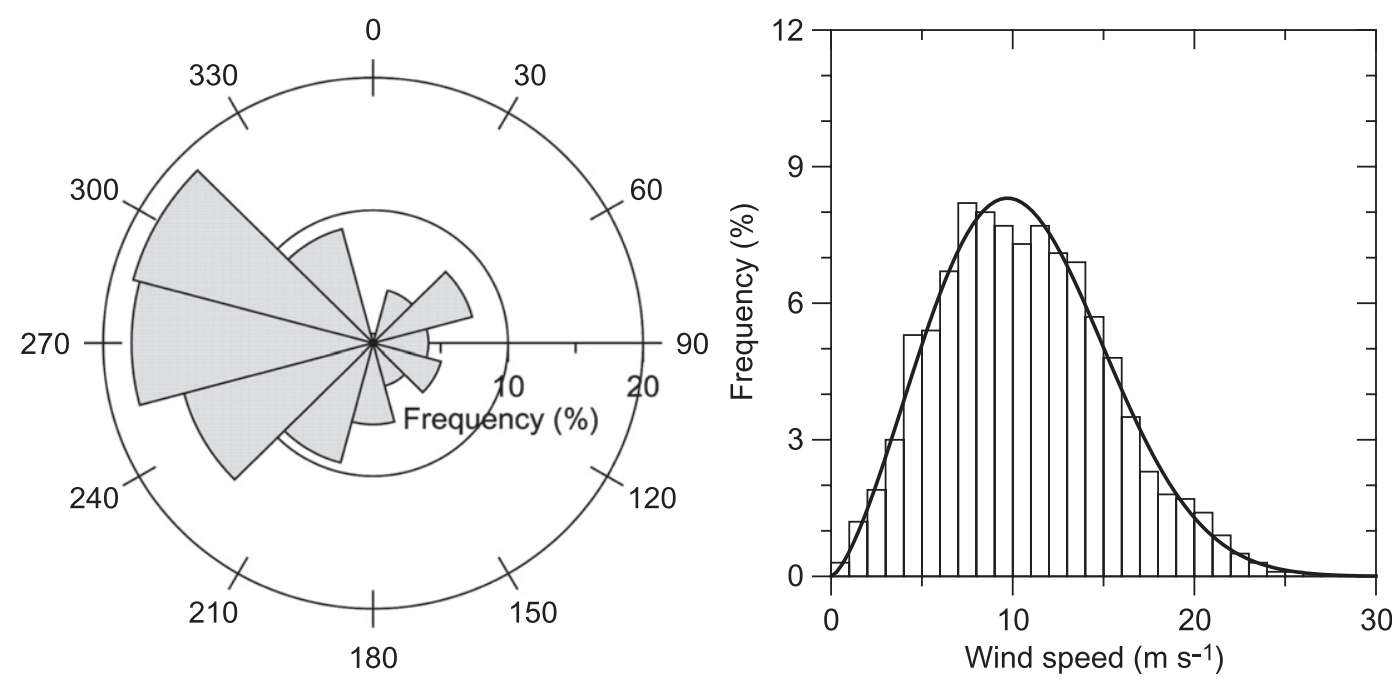

FIG. 1. (left) Wind rose and (right) wind speed distribution from lidar data at $100 \mathrm{~m}$ for the period 23 Apr 2010-31 Mar 2011 at Høvsøre. The fitted Weibull distribution of the wind speed is shown with a solid line.

a westerly direction, corresponding to wind from the sea. As a consequence, the results from the analysis were influenced by the formation of internal boundary layers downwind from the abrupt change between sea and land. Floors et al. (2011) showed that the height of the internal boundary layer was typically $100 \mathrm{~m}$ at the measuring site.

The study required coincident model and measurement (mast and lidar) profiles. To achieve high-quality data, a threshold sensitivity limit was imposed on the lidar data; this limit required that all lidar measurements within a profile up to $600 \mathrm{~m}$ have a CNR $>-22 \mathrm{~dB}$, in accordance with Floors et al. (2013). At least 31\% of profiles satisfied this criterion, corresponding to 15359 ten-minute mean profiles.

\section{a. Mean wind profile}

Figure 2 shows the profiles of the mean wind speed and wind direction The wind direction of the lidar is relative to the direction at the mast at $100 \mathrm{~m}$. It can be seen that the effect of nudging on these profiles is small. Near the ground, the agreement between the measured and modeled values of the wind speed is good; above approximately $60 \mathrm{~m}$, the model underestimates the mean wind speed. For the wind direction above $100 \mathrm{~m}$,
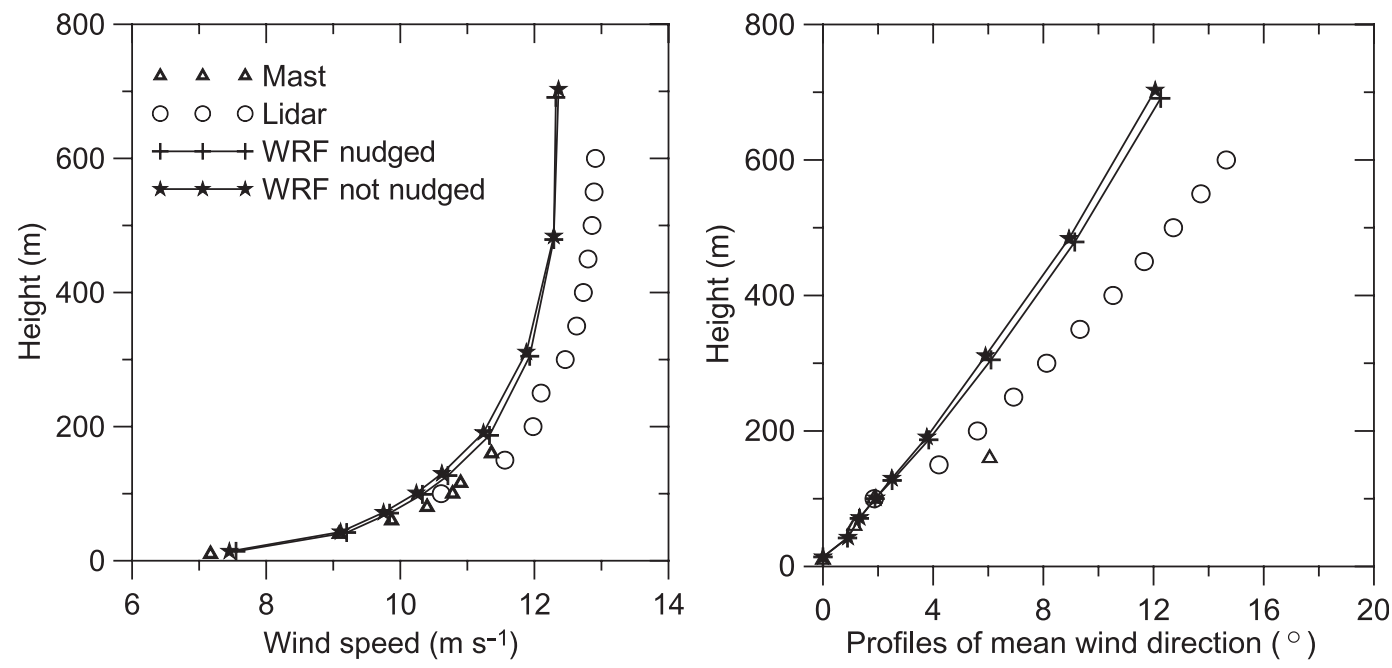

FIG. 2. Profiles of (left) mean wind speed and (right) mean wind direction. The lidar wind profile in the right panel is relative to the mean direction at the mast at $100 \mathrm{~m}$. 

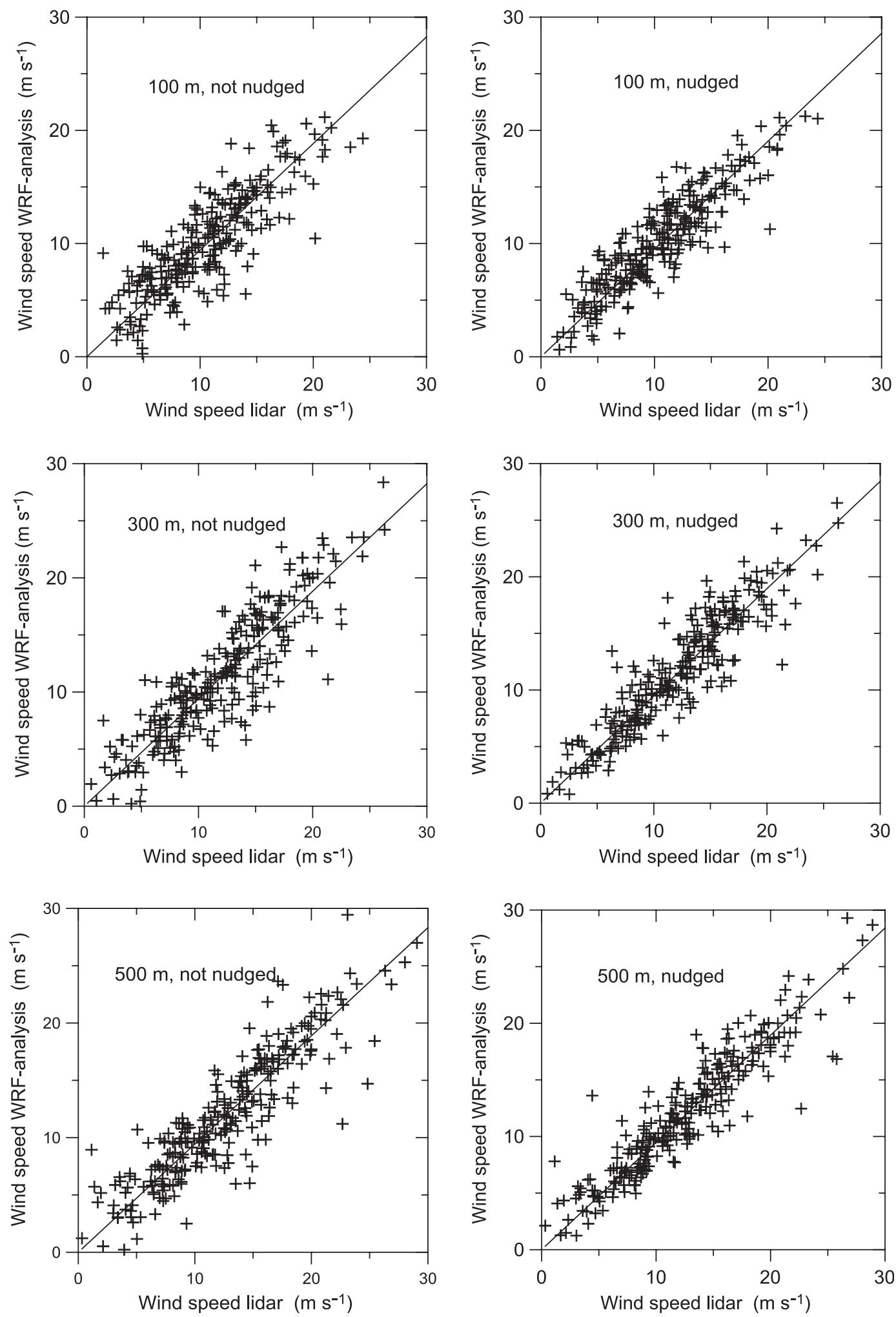

FIG. 3. Scatterplots of wind speed measurements and WRF model simulations at 100, 300, and $500 \mathrm{~m}$ height (left) without nudging and (right) with nudging. Only every 60th data point is shown for clarity. 
the WRF analysis produced a smaller change with height than observed.

\section{b. Scatterplots}

The scatter between wind speed measurements and model results at 100, 300, and $500 \mathrm{~m}$ is shown in Fig. 3, and a comparison between model and measurements is provided in Table 1. It can be seen that both model simulations (with and without nudging) underpredict the wind speed, but the nudged simulations are somewhat closer to the measurements. The underprediction increases with height, being around 3\% (normalized bias) at $100 \mathrm{~m}$ and increasing to $4 \%-5 \%$ at 300 and $500 \mathrm{~m}$. Accordingly, the slope coefficient is always less than 1 and is nearly constant with height.

The root-mean-square error (RMSE) is used to illustrate the comparison between the individual measurements and the model prediction. There is a clear improvement in the performance of the model when it is nudged; RMSE is approximately $2.2 \mathrm{~m} \mathrm{~s}^{-1}$ at $100 \mathrm{~m}$ when the model is nudged and is approximately $2.6 \mathrm{~m} \mathrm{~s}^{-1}$ when the model is not nudged. RMSE slightly increases with height, reaching $2.3 \mathrm{~m} \mathrm{~s}^{-1}$ at $300 \mathrm{~m}$ for the nudged model and $2.9 \mathrm{~m} \mathrm{~s}^{-1}$ at $500 \mathrm{~m}$ for the model with no nudging.

\section{Weibull distribution}

The long-term frequency distribution of the horizontal wind speed is often presented in the form of a twoparameter Weibull distribution:

$$
f(u)=\frac{k}{A}\left(\frac{u}{A}\right)^{k-1} \exp \left[-\left(\frac{u}{A}\right)^{k}\right],
$$

where $f(u)$ is the frequency of occurrence of the wind speed $u$. In this Weibull distribution, the scale parameter $A$ has the same units as the wind speed and $k$ is the shape parameter.

The $A$ and $k$ parameters are related to the average wind speed $\bar{u}$ for the entire distribution through the gamma function $\Gamma$ :

$$
\bar{u}=A \Gamma(1+1 / k) .
$$

For typical wind speed distributions over homogeneous terrain, $k$ falls in the range of 1.5-3 (Wieringa 1989; Lun and Lam 2000), and $A$ is near proportional to the mean wind speed for typical $k$ values (Bhattacharya and Bhattacharjee 2010).

This distribution has received considerable attention in relation to wind-energy applications because it attempts to account for the frequency of high wind speeds, which has an important contribution to wind power
TABLE 1. Comparison between model and measurements: slope coefficient $a$ of a linear fit through the origin ( $Y=a X$, where $Y$ is the modeled wind speed and $X$ is the measured wind speed); bias $(\bar{Y}-\bar{X})$, where the bar denotes average; normalized bias $100[(\bar{Y}-\bar{X}) / \bar{X}]$, and RMSE $\left\{=\left[\sum_{i=1}^{N}\left(Y_{i}-X_{i}\right)^{2} / N\right]^{1 / 2}\right.$, where $N$ is

\begin{tabular}{|c|c|c|}
\hline Simulation & With nudging & Without nudging \\
\hline \multicolumn{3}{|c|}{ Height $=100 \mathrm{~m}$} \\
\hline Slope coef & 0.95 & 0.94 \\
\hline $\operatorname{Bias}\left(\mathrm{m} \mathrm{s}^{-1}\right)$ & -0.28 & -0.37 \\
\hline Normalized bias (\%) & -2.60 & -3.45 \\
\hline $\operatorname{RMSE}\left(\mathrm{m} \mathrm{s}^{-1}\right)$ & 2.18 & 2.61 \\
\hline \multicolumn{3}{|c|}{ Height $=300 \mathrm{~m}$} \\
\hline Slope coef & 0.95 & 0.94 \\
\hline $\operatorname{Bias}\left(\mathrm{m} \mathrm{s}^{-1}\right)$ & -0.53 & -0.58 \\
\hline Normalized bias (\%) & -4.22 & -4.63 \\
\hline $\operatorname{RMSE}\left(\mathrm{m} \mathrm{s}^{-1}\right)$ & 2.30 & 2.83 \\
\hline \multicolumn{3}{|c|}{ Height $=500 \mathrm{~m}$} \\
\hline Slope coef & 0.94 & 0.94 \\
\hline $\operatorname{Bias}\left(\mathrm{m} \mathrm{s}^{-1}\right)$ & -0.57 & -0.57 \\
\hline Normalized bias (\%) & -4.44 & -4.45 \\
\hline $\operatorname{RMSE}\left(\mathrm{m} \mathrm{s}^{-1}\right)$ & 2.25 & 2.86 \\
\hline
\end{tabular}
the number of samples\}.

yield. Here, we derive the $A$ and $k$ parameters in the Weibull distribution from measurements and simulations using the Climate Analyst utility in the Wind Atlas Analysis and Application Program (WAsP), version 10 (Troen and Petersen 1989). The results were checked by a graphical method described in Scholz (2008).

\section{a. Scale parameter}

The comparison of the modeled scale parameter $A$ with measurements shows similarities with the wind speed. Below $60 \mathrm{~m}$, simulations predict the $A$ parameter well. Above $60 \mathrm{~m}$, the simulated scale parameter gradually decreases relative to the measurements. As with the mean wind speed, it can be seen that the sensitivity to nudging is minor (Fig. 4, left panel).

\section{b. Shape parameter}

Contrary to the scale parameter, which has a mostly smooth vertical profile, the shape parameter $k$ has a very characteristic vertical profile. It increases from the surface value to a maximum located at around $100-200 \mathrm{~m}$, and then above this layer it decreases toward its tropospheric value. The shape of the profile is related to the balance between the diurnal variation of the meteorological conditions near the surface and the variability of the synoptic conditions prevailing in the region. An assessment of the $k$ profile from model output illustrates the ability of the model to simulate this balance.

We found that nudging has a large impact on the shape parameter. When nudged, the simulation agrees 

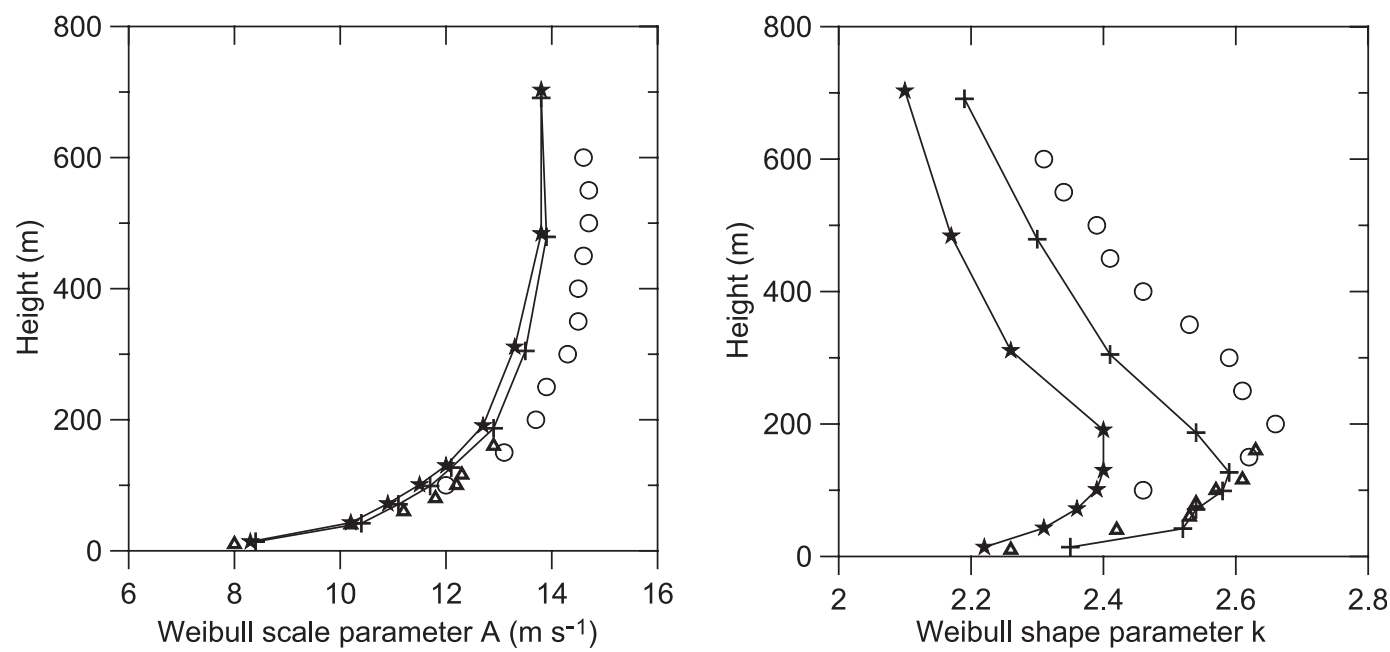

FIG. 4. Profiles of (left) scale parameter and (right) shape parameter in the Weibull distribution. The legend is given in Fig. 2.

very well with the measurements up to $100 \mathrm{~m}$ while it continues to underestimate the shape parameter above this height. The height of the internal boundary layer at Høvsøre is approximately $100 \mathrm{~m}$ and can influence the scale and shape parameter. When there is no nudging in the model, the underprediction is greater at all heights (Fig. 4, right panel).

\section{Power density}

Wind power density is a function of height and is roughly proportional to the cube of the wind speed. We calculated wind power densities using the Climate Analyst utility in WAsP. Near the ground (Fig. 5), we found good agreement between the power density estimated from the measurements and the model simulations. Above $60 \mathrm{~m}$, the power density began to be underestimated by the simulations. Nudging displayed no impact on the simulations up to $300 \mathrm{~m}$, although there was evidence for some slightly negative effect from nudging above this level.

\section{Discussion and conclusions}

A full year of measurements of the wind profile performed at a rural coastal site in a windy climate has been analyzed and compared with simulations made with the WRF model. The measurements were carried out with a 600-m-range wind Doppler lidar in combination with a tall meteorological mast. In this study, we focused on the impact of nudging on the profiles of wind and Weibull distribution parameters. We found that 1) nudging had a minor effect on the profiles of the scale parameter in the Weibull distribution, the mean wind speed, the change of wind direction with height, and the wind power density and 2) nudging had a major effect on the profile of the shape parameter in the Weibull distribution and the RMSE between modeled and measured wind speed.

The wind speed and its Weibull distribution are key elements in wind-energy studies. From Fig. 4 it can be seen that nudging reduces the underestimation of both the scale and shape parameters. Underestimation of the scale parameter suggests underestimation of the power density. In contrast, underestimation of the shape

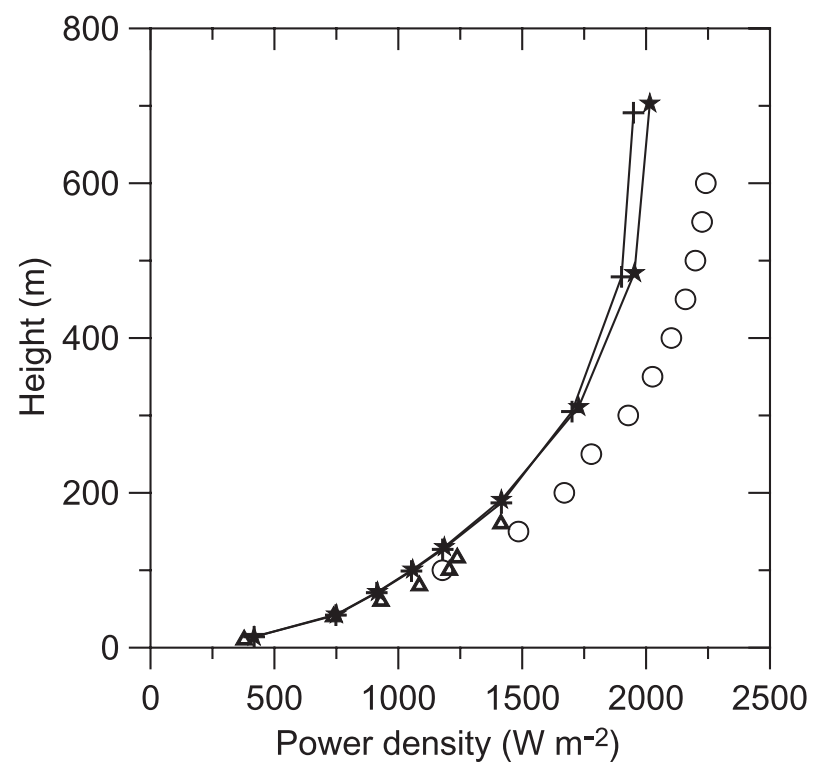

FIG. 5. Profiles of power density. The legend is given in Fig. 2. 
parameter signifies higher variability of the wind speed and hence larger power density. The combination of these two effects results in nudging having very little influence on the power density estimations up to $300 \mathrm{~m}$.

Acknowledgments. The study was supported by the Danish Council for Strategic Research, Project 2104-080025 named "Tall Wind," the Nordic Centre of Excellence program CRAICC, and the Danish Environmental Agency Project M 112-00270. We are thankful to the Test and Measurements section of DTU Wind Energy for the maintenance of the Høvsøre database and to Dr. Ewan O'Connor, who kindly read through the manuscript.

\section{REFERENCES}

Bhattacharya, P., and R. Bhattacharjee, 2010: A study on Weibull distribution for estimating the parameters. J. Appl. Quant. Methods, 4, 234-241.

Boilley, A., and J.-F. Mahfouf, 2012: Assimilation of low-level wind in a high-resolution mesoscale model using the back and forth nudging algorithm. Tellus, 64A, 18697, doi:10.3402/ tellusa.v64i0.18697.

Chen, F., and J. Dudhia, 2001: Coupling an advanced land surfacehydrology model with the Penn State-NCAR MM5 modeling system. Part I: Model implementation and sensitivity. Mon Wea. Rev., 129, 569-585.

Deng, A., and D. R. Stauffer, 2005: On improving 4-km mesoscale model simulations. J. Appl. Meteor., 45, 361-381.

Floors, R., S. E. Gryning, A. Peña, and E. Batchvarova, 2011: Analysis of diabatic flow modification in the internal boundary layer. Meteor. Z., 20, 649-659.

- C. L. Vincent, S. E. Gryning, A. Peña and E. Batchvarova, 2013: The wind profile in the coastal boundary layer: Wind lidar measurements and numerical modelling. Bound.-Layer Meteor., doi:10.1007/s10546-012-9791-9, in press.

Gryning, S. E., E. Batchvarova, B. Brümmer, H. Jørgensen, and S. Larsen, 2007: On the extension of the wind profile over homogeneous terrain beyond the surface boundary layer. Bound.-Layer Meteor., 124, 251-268.

Hahmann, A. N., D. Rostkier-Edelstein, T. T. Warner, F. Vandenberghe, Y. Liu, R. Babarsky, and S. P. Swerdlin,
2010: A reanalysis system for the generation of mesoscale climatographies. J. Appl. Meteor., 49, 954-972.

Lo, J. C. F., Z. L. Yang, and R. A. Pielke Sr., 2008: Assessment of three dynamical climate downscaling methods using the Weather Research and Forecasting (WRF) model. J. Geophys. Res., 113, D09112, doi:10.1029/2007JD009216.

Lun, I. Y. F., and J. C. Lam, 2000: A study of the Weibull parameters using long-term observations. Renewable Energy, 20 (2), 145-153.

Nakanishi, M., 2001: Improvement of the Mellor-Yamada turbulence closure model based on large-eddy simulation data. Bound.-Layer Meteor., 99, 349-378.

O'Connor, E. J., A. J. Illingworth, I. M. Brooks, C. D. Westbrook, R. J. Hogan, F. Davies, and B. J. Brooks, 2010: A method for estimating the turbulent kinetic energy dissipation rate from a vertically pointing Doppler lidar, and independent evaluation from balloon-borne in situ measurements. J. Atmos. Oceanic Technol., 27, 1652-1664.

Otte, T. L., 2007: The impact of nudging in the meteorological model for retrospective air quality simulations. Part I: Evaluation against national observation networks. J. Appl. Meteor. Climatol., 47, 1853-1867.

Pedersen, T. F., 2004: Characterisation and classification of RIS $\varnothing$ P2546 cup anemometer. Ris $\emptyset$ National Laboratory Rep. Ris $\varnothing$ R-1364 (ed. 2) (EN), 54 pp. [Available online at http://www. risoe.dk/rispubl/VEA/veapdf/ris-r-1364_ed2.pdf.]

Scholz, F., 2008: Weibull probability paper. Internal Note, $11 \mathrm{pp}$. [Available online at www.stat.washington.edu/fritz/ DATAFILES498B2008/WeibullPaper.pdf.]

Skamarock, W. C., J. B. Klemp, J. Dudhia, D. O. Gill, D. M. Barker, M. G. Duda, X.-Y. Huang, W. Wang, and J. G. Powers, 2008: A description of the Advanced Research WRF version 3. NCAR Tech. Note NCAR/TN-475+STR, 113 pp.

Thompson, G., R. M. Rasmussen, and K. Manning, 2004: Explicit forecasts of winter precipitation using an improved bulk microphysics scheme. Part I: Description and sensitivity analysis. Mon. Wea. Rev., 132, 519-542.

Troen, I., and E. L. Petersen, 1989: European Wind Atlas. Commission of the European Communities Directorate-General for Science, Research and Development, Brussels, Belgium, Ris $\varnothing$ National Laboratory, Roskilde, Denmark, 656 pp.

von Storch, H., H. Langenberg, and F. Feser, 2000: A spectral nudging technique for dynamical downscaling purposes. Mon. Wea. Rev., 128, 3664-3673.

Wieringa, J., 1989: Shapes of annual frequency distributions of wind speed observed on high meteorological masts. Bound.Layer Meteor., 47, 85-111. 